\title{
Parametric Optimization of Eicher 11.10 Chassis Frame for Weight Reduction Using FEA-DOE Hybrid Modeling
}

\author{
Tushar M. Patel ${ }^{1}$, Dr. M. G. Bhatt ${ }^{2}$, Harshad K. Patel ${ }^{3}$ \\ ${ }^{I}$ Research Scholar, Mewar University, Gangrar, Rajasthan, India. \\ ${ }^{2}$ Associate Professor, SSEC, Bhavnagar, Gujarat, India \\ ${ }^{3}$ ME Scholar, LDRP-ITR, Gandhinagar, Gujarat, India.
}

\begin{abstract}
The chassis serves as a backbone for supporting the body and different parts of the automobile. It should be rigid enough to withstand the shock, twist, vibration and other stresses. Along with strength, an important consideration in chassis design is to have adequate bending stiffness. The main objective of the research is to obtain the minimum weight of Eicher 11.10 chassis frame. The chassis frame is made of two side members joined with a series of cross members. The number of cross members, their locations, cross-section and the sizes of the side and the cross members becomes the design variables. The chassis frame model is to be developed in Solid works and analyzed using Ansys. Since the no. of parameters and levels are more, the probable models are too many. So, to select optimum parameters among them large no of modeling and analysis work is involved which consumes more time. To overcome this problem TAGUCHI method along with FEA is use. The weight reduction of the side bar is achieved by changing the Parameters using orthogonal array. Then FEA is performed on those models to get the best solution. This method can save material used, production cost and time.
\end{abstract}

Keywords: Parametric optimization, Chassis frame, FE analysis, FEA-DOE hybrid modeling, Weight reduction

\section{Introduction}

In automotive type vehicles, the frame is considered to be the foundation or "Backbone". The frame in conjunction with the vehicles suspensions, axles, wheels and tires makeup the principal load-carrying components of a vehicle. The frame and other components not only carry the weight of the vehicle, but its payload as well. In addition to the load carrying function, the frame and suspension also transfer the forces from the axles to the vehicle structure. This includes the forces of brake torque reaction as well as the drive forces that propel or move the vehicle. The frame acts as a foundation or base for the body structure of vehicles, the axles with their suspensions and the engine/transmission package. The frame must be rigid enough to support or carry all the loads and forces that the vehicle is subjected to in operation. A frame must also be flexible enough to handle shock loads and the twists, bends, sway and sag that it encounters under different road or load conditions. A frame that is too rigid is most likely to fail even under normal operations. Ideally the frame should be able to flex under different situations, while being able to return to its original shape when loads or forces are removed.

According to European Commission of Research \& Innovation in transport, the reduction of fuel consumption and $\mathrm{CO}_{2}$ emissions is one of the most important challenges facing the automotive industry. One way to reduce consumption is by reducing a weight of vehicle. Thus, the project goal is to provide the basis to save millions of tone of fuel and carbon dioxide due to significantly reduced vehicle weight. About one-third of a passenger car's total fuel consumption directly depends on its weight. A weight reduction of $100 \mathrm{~kg}$ represents a fuel savings of between $0.3-0.5$ litres for every $100 \mathrm{~km}$ driven according to industry estimates [4].

The main objective of the project is to reduce the weight of Eicher 11.10 chassis frame. This optimum design is being constrained by the maximum strength and stiffness requirements. The chassis frame is made of two side members joined with a series of cross members. The number of cross members, their locations, crosssection and the sizes of the side and the cross members are the design variables. As the chassis frame is analysed using the finite element techniques, appropriate model of the frame is to be developed. The weight reduction is achieved by changing the Parameters (Size Optimization) of the side bar and cross bar. Then FEA is performed on those models to get the best solution. Since the numbers and levels of parameters are more, the probable models are too many. So, to select optimum parameters among them large numbers of modelling and analysis work is involved which consumes more time. To overcome this problem, Design of Experiment technique can be use along with FEA.

\section{Literature Review}

Structural optimization using computational tools has become a major research field in recent years. Methods commonly used in structural analysis and optimization may demand considerable computational cost, 
depending on the problem complexity. Among these various techniques of DOE may be combined with classic analysis, to reduce the computational effort without affecting the final solution quality. Ajaykumar Menon et al. (2005) proposed an automation process in MATLAB that incorporates a response surface approximating tool called MQR. The results obtained from the proposed method were compared with ANSYS Design Xplorer goal driven optimization which was based on DOE and ANSYS First order optimization technique [6]. D. M. Chauhan et al. (2006) Optimized weight of the HMT (Hydraulic Modular Trailer) to have higher pay load capacity. Frame was optimized using design optimization module available in ANSYS using first order optimization method. They have concluded that frame was optimized and feasible design was obtained with 52 $\%$ reduction in mass. This reduction in mass of the frame increases the payload capacity by 4.900 tones approximately. During optimization of frame, it was found that web thicknesses value should be kept more than the flange thicknesses value for side long member [8]. Wen-Hsien Hsu et al. (2009) has been used a FEM-based Taguchi method to investigate the effects of various factors to find the robust design of the body cage. The FEM-based Taguchi methods have effectively decreased the time and efforts required for evaluating the design variables of implants and had fairly assessed the contribution of each design variable [1]. Bappa Acherjee et al. (2012) carried out a systematic investigation on laser transmission contour welding process using finite element analysis (FEA) and design of experiments (DOE) techniques. A three dimensional thermal model was developed to simulate the laser transmission contour welding process with a moving heat source. Design of experiments was employed to plan the experiments and to develop mathematical models based on simulation results [2].

\section{Material of Model}

The material for the chassis is defined ST 52 which is widely used material for the chassis. The material properties are as shown in Table 1.

Table 1: Material properties of chassis [5]

\begin{tabular}{|l|l|}
\hline Material & ST 52 \\
\hline Modulus of Elasticity E & $2 \times 10^{5} \mathrm{MPa}$ \\
\hline Poisson's Ratio & 0.3 \\
\hline Tensile Strength & $520 \mathrm{MPa}$ \\
\hline Yield Strength & $360 \mathrm{MPa}$ \\
\hline
\end{tabular}

\section{Methodology}

As an important subject in the statistical design of experiments, the Taguchi method is a collection of mathematical and statistical techniques useful for the parametric optimization and analysis of problems in which a response of interest is influenced by several variables and the objective is to optimize this response.

Taguchi method is used to examine the relationship between a response and a set of quantitative experimental variables or factors.

Steps for the Experiment:

- Formulation of the problem - the success of any experiment is dependent on a full understanding of the nature of the problem.

- Selection of the output performance characteristics most relevant to the problem.

- Selection of parameters.

- Selection of factor levels.

- Design of an appropriate Orthogonal Array (OA).

- To Perform FEA with appropriate set of parameters.

- Statistical analysis and interpretation of experimental results.

- Modeling and FEA with optimum parameter set for validation

Flow chart of experiment is given in Figure 1. 


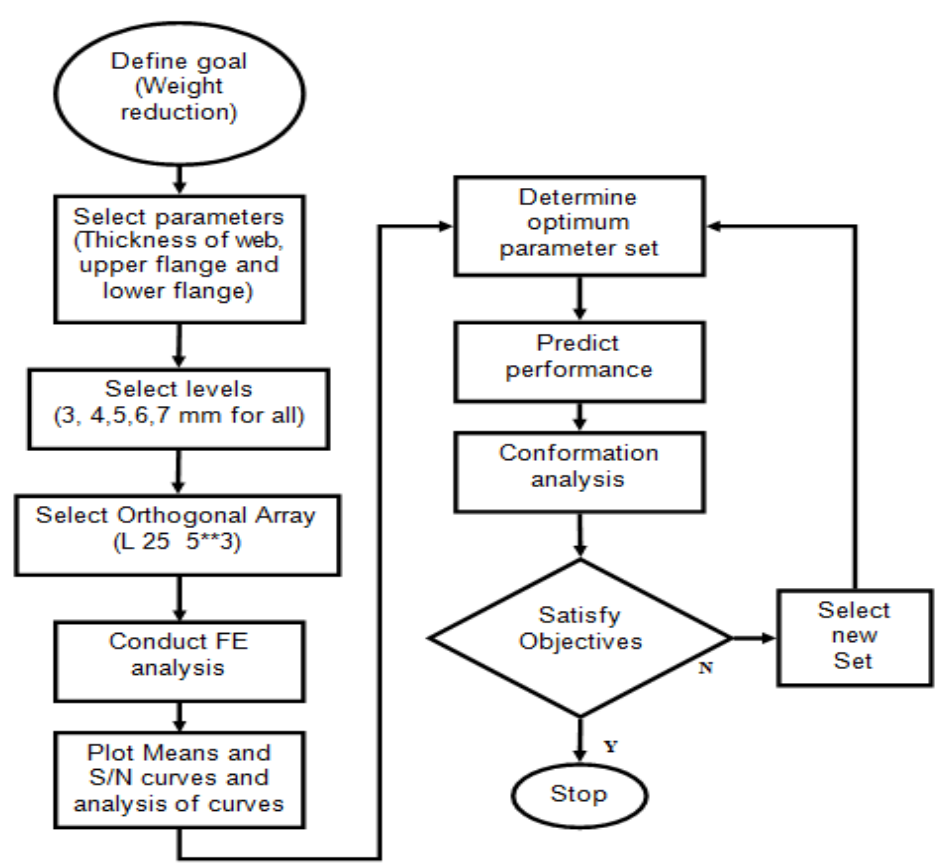

Fig. 1: Flow chart of Experiment [7]

\section{Experimental Method}

Experiments are planned according to Taguchi's L25 orthogonal array for web, upper flange and lower flange as shown in fig.2. It has 25 rows corresponding to the number of testes with 5 columns at five levels and 3 parameters as shown in Table 2. This orthogonal array is chosen due to its capability to check the interactions among factors.



Fig. 2: C channel

The experimental results are then transferred in to a Signal to Noise $(\mathrm{S} / \mathrm{N})$ ratio. There are three categories of quality characteristic in the analysis of the $\mathrm{S} / \mathrm{N}$ ratio, (i) the-lower-the-better, (ii) the-higher-thebetter and (iii) the-nominal-the better. Regardless of the category of the quality characteristic, process parameter settings with the highest $\mathrm{S} / \mathrm{N}$ ratio always yield the optimum quality with minimum variance. The category thelower-the-better was used to calculate the $\mathrm{S} / \mathrm{N}$ ratio for both quality characteristics stress and deflection, according to the equation (1):

$$
S / N=-10 \log _{10}\left[\frac{1}{n} \sum_{i=1}^{n} \mathrm{Yi}^{2}\right]
$$

Where, 
$S / N=$ Signal to noise ratio

$\mathrm{n}=$ Number of repetitions of experiment

$\mathrm{Y} i=$ Measured value of quality characteristic

Table 2: Factors and their levels

\begin{tabular}{|c|c|c|c|c|c|}
\hline Factor & Level 1 & Level 2 & Level 3 & Level 4 & Level 5 \\
\hline Thickness of Web (mm) & 3 & 4 & 5 & 6 & 7 \\
\hline Thickness of Upper flange (mm) & 3 & 4 & 5 & 6 & 7 \\
\hline Thickness of Lower flange (mm) & 3 & 4 & 5 & 6 & $\mathbf{7}$ \\
\hline
\end{tabular}

For finding out optimum thickness of web, upper flange and lower flange the value of shear stress, deflection and weight is measured using ANSYS. Series of analysis is conducted to obtain the optimum weight for allowable stress and deflection condition. Taguchi method is being applied to select the control factors levels (thickness of web, upper flange and lower flange) to come up with optimal response value (weight, shear stress and deflection).

\section{Result And Discussion}

The shear stress and deflection are measured for each set of parameter using FEA in Ansys, and the Results of FEA are analysed using Minitab 16. Minitab offers four types of designed experiments: factorial, response surface, mixture, and Taguchi (robust). The steps follows in Minitab to create, analyse, and graph an experimental design are similar for all design types. After conducting the analysis and entering the results, Minitab provides several analytical and graphing tools to help understand the results. Minitab version 16 is used for the analysis of result obtained by Finite element analysis. The S/N ratio for minimum shear stress and deflection are coming under "Smaller-is-better" characteristic, which can be calculated as logarithmic transformation of the loss function.

Taguchi designs experiments using especially constructed tables known as "orthogonal arrays" (OA). The use of these tables makes the design of experiments very easy and consistent.

From the Table 3 it is identified that minimum shear stress value $70.491 \mathrm{MPa}$ and minimum deflection value $2.7419 \mathrm{~mm}$ are obtained at the experiment no 25 having values of thickness of web, thickness of upper flange and thickness of lower flange $7 \mathrm{~mm}, 7 \mathrm{~mm}$ and $6 \mathrm{~mm}$ respectively.

Table 3: Experimental Results Table

\begin{tabular}{|c|c|c|c|c|c|c|}
\hline $\begin{array}{c}\text { Sr. } \\
\text { No. }\end{array}$ & $\begin{array}{c}\text { Thickness } \\
\text { of web } \\
(\mathbf{m m})\end{array}$ & $\begin{array}{c}\text { Thickness of } \\
\text { upper flange } \\
(\mathbf{m m})\end{array}$ & $\begin{array}{c}\text { Thickness of } \\
\text { lower flange } \\
(\mathbf{m m})\end{array}$ & $\begin{array}{c}\text { Weight } \\
(\mathbf{K g})\end{array}$ & $\begin{array}{c}\text { Shear stress } \\
(\mathbf{M P a})\end{array}$ & $\begin{array}{c}\text { Deflection } \\
(\mathbf{m m})\end{array}$ \\
\hline 1 & 3 & 3 & 3 & 222.2 & 150.45 & 5.0147 \\
\hline 2 & 3 & 4 & 4 & 237 & 120.35 & 4.5912 \\
\hline 3 & 3 & 5 & 5 & 250.5 & 130.24 & 3.7103 \\
\hline 4 & 3 & 6 & 6 & 263.8 & 114.8 & 3.4359 \\
\hline 5 & 3 & 7 & 7 & 277.14 & 98.635 & 3.1076 \\
\hline 6 & 4 & 3 & 4 & 248.32 & 129.73 & 4.6805 \\
\hline 7 & 4 & 4 & 5 & 262.39 & 127.19 & 4.2384 \\
\hline 8 & 4 & 5 & 6 & 275.5 & 118.78 & 3.6374 \\
\hline 9 & 4 & 6 & 7 & 289 & 109.686 & 3.4383 \\
\hline 10 & 4 & 7 & 3 & 279.4 & 123.99 & 3.6753 \\
\hline 11 & 5 & 3 & 5 & 279.44 & 123.3 & 3.9242 \\
\hline 12 & 5 & 4 & 6 & 288.4 & 115.77 & 3.4818 \\
\hline 13 & 5 & 5 & 7 & 301.76 & 110.39 & 3.1643 \\
\hline 14 & 5 & 6 & 3 & 281.69 & 122.35 & 3.437 \\
\hline 15 & 5 & 7 & 4 & 295.07 & 119.43 & 3.2619 \\
\hline 16 & 6 & 3 & 6 & 301.475 & 112.22 & 3.4309 \\
\hline 17 & 6 & 4 & 7 & 314.66 & 99.647 & 3.0272 \\
\hline 18 & 6 & 5 & 3 & 294.88 & 111.44 & 3.3299 \\
\hline
\end{tabular}




\begin{tabular}{|l|l|l|l|l|l|l|}
19 & 6 & 6 & 4 & 308.06 & 104.21 & 3.0888 \\
\hline 20 & 6 & 7 & 5 & 321.25 & 102.69 & 2.9097 \\
\hline 21 & 7 & 3 & 7 & 327.75 & 107.2 & 3.1379 \\
\hline 22 & 7 & 4 & 3 & 308.27 & 109.91 & 3.3075 \\
\hline 23 & 7 & 5 & 4 & 321.26 & 103.59 & 3.0497 \\
\hline 24 & 7 & 6 & 5 & 334.25 & 98.794 & 2.8711 \\
\hline 25 & 7 & 7 & 6 & 347.23 & 70.491 & 2.7419 \\
\hline
\end{tabular}

Main Effects Plot for Mean data and S/N ratio data are shown in Fig. 3, 4, 5, 6, 7 and 8 that shows effect of thickness of web, thickness of upper flange and thickness of lower flange on weight, shear stress and deflection.

The effects of thickness of web, thickness of upper flange and thickness of lower flange on weight of chassis frame are shown in Fig. 3 and Fig. 4.

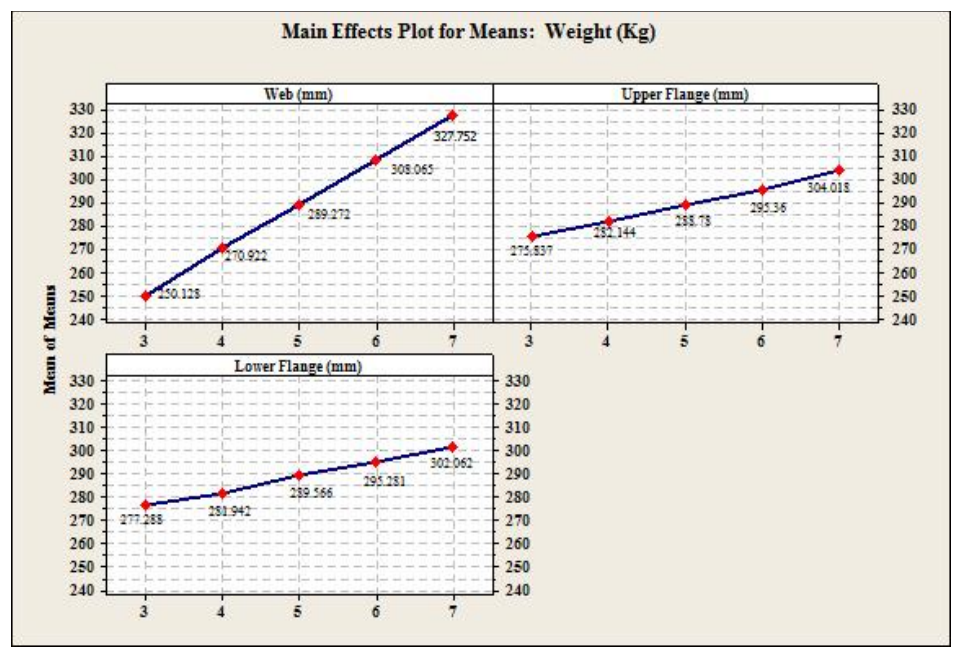

Fig. 3: Main Effects Plot for Mean data: weight

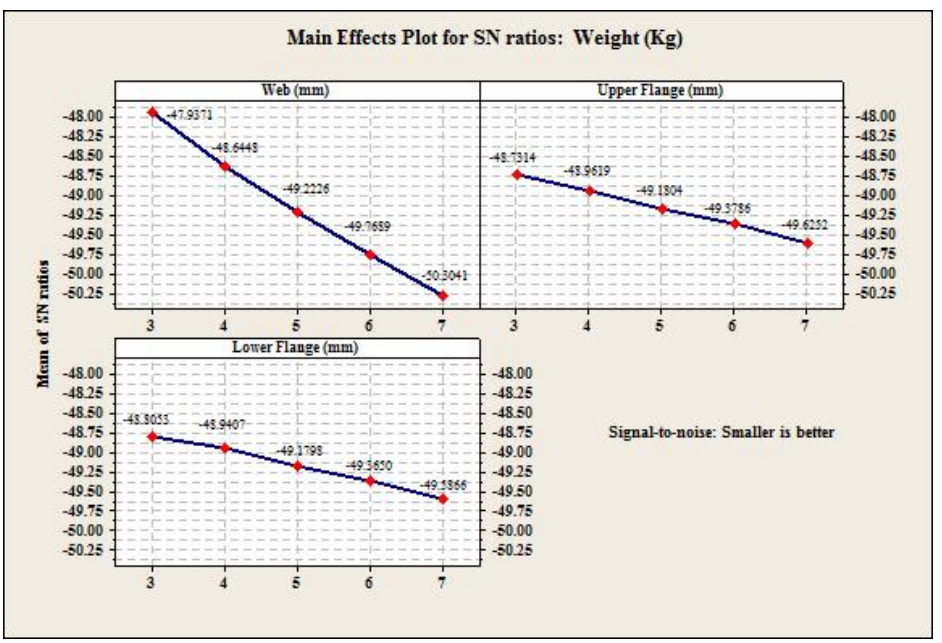

Fig. 4: Main Effects Plot for S/N ratio data: Weight

In the investigation, it has been found that as the values of web thickness, upper flange thickness and lower flange thickness are increased, the weight is increased and when these values are decreased the weight is also decreased as shown in Fig. 3 and Fig. 4.

The effects of thickness of web, thickness of upper flange and thickness of lower flange on shear stress of chassis frame are shown in Fig. 5 and Fig. 6.

The FEA done on the chassis model and generated shear stress values are given in Table 3. Based on static safety factor theory, the magnitude of safety factor for this structure is 1.43. J. P. Vidosic recommends some value of safety factor for various condition of loading and material of structures. The value of 1.5 to 2 for 
well known materials under reasonably environmental condition, subjected to loads and stresses that can be determined readily [4]. It is necessary to reduce the stress magnitude of critical point in order to get the satisfy $\mathrm{SF}$ value of truck chassis. The truck chassis can be modified to increase the value of SF especially at critical point area. The permissible value of shear stress for material ST 52 is 360/3 = $120 \mathrm{Mpa}$ (considering factor of safety is 3 for design). The formula of Safety Factor (SF) is defined by [5]

Design stress $=$ yield strength $/$ safety factor

$$
\begin{aligned}
& =360 / 3 \\
& =120 \mathrm{MPa}
\end{aligned}
$$

The corresponding value of $\mathrm{S} / \mathrm{N}$ ratio is -41.584 for smaller is better characteristics.

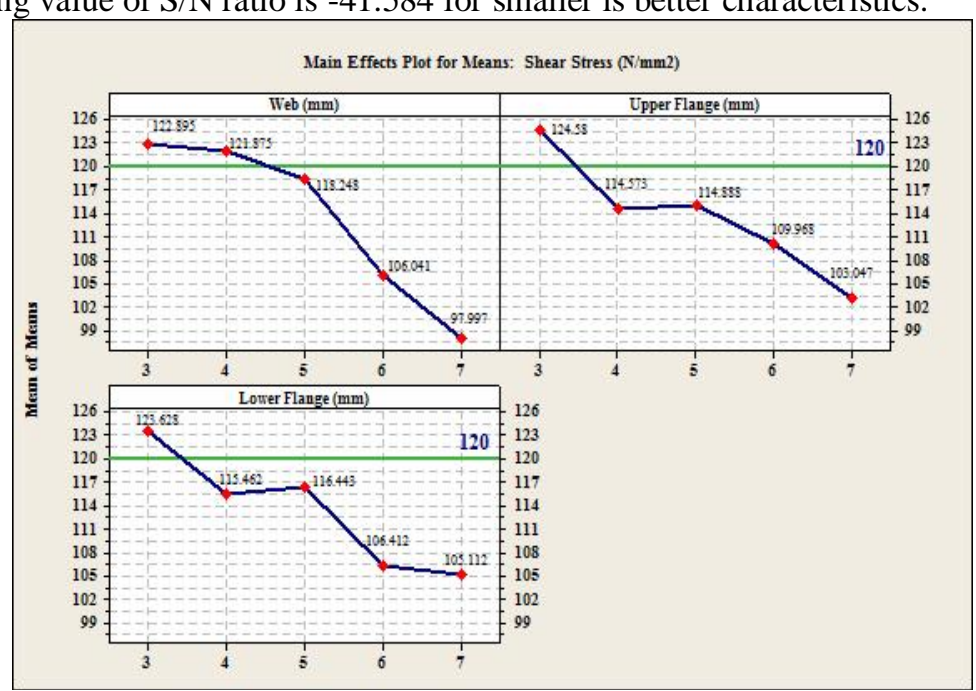

Fig. 5: Main Effects Plot for Mean data: shear stress

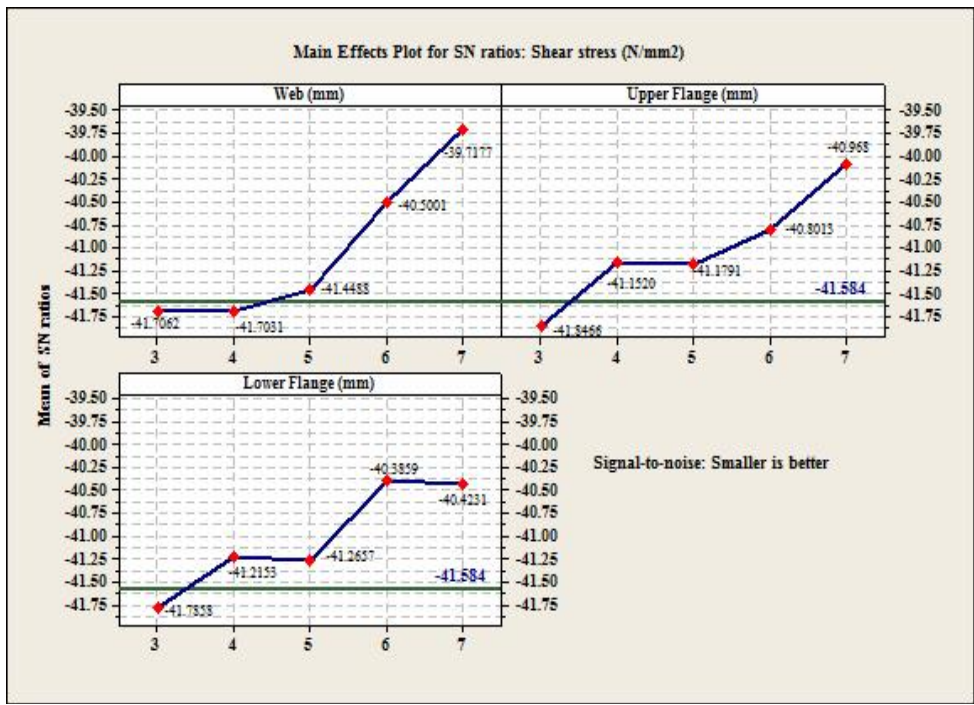

Fig. 6: Main Effects Plot for S/N ratio data: Shear stress

Results of Main Effects Plot for Mean data for weight (Fig. 7) and Main Effects Plot for S/N ratio data for weight (Fig. 8) analysis are given in Table 4. As per the results chassis with $5 \mathrm{~mm}$ web thickness, $4 \mathrm{~mm}$ upper flange thickness and $4 \mathrm{~mm}$ lower flange thickness is having optimum weight.

Table 4: Analysis of Shear stress

\begin{tabular}{|c|c|c|c|}
\hline & $\begin{array}{c}\text { Web Thickness } \\
(\mathbf{m m})\end{array}$ & $\begin{array}{c}\text { Upper Flange } \\
\text { Thickness } \\
(\mathbf{m m})\end{array}$ & $\begin{array}{c}\text { Lower Flange } \\
\text { Thickness } \\
(\mathbf{m m})\end{array}$ \\
\hline $\begin{array}{c}\text { Generated Stress > } \\
\mathbf{1 2 0}\end{array}$ & 3 & 3 & 3 \\
For Size & 4 & & \\
\hline Generated Stress < & 5 & 4 & 4 \\
\hline
\end{tabular}




\begin{tabular}{|c|c|c|c|}
\hline $\mathbf{1 2 0}$ & 7 & 6 & 6 \\
For Size & & 7 & 7 \\
\hline Optimum Size & 5 & 4 & 4 \\
\hline
\end{tabular}

The effects of thickness of web, thickness of upper flange and thickness of lower flange on deflection of chassis frame are shown in Fig. 7 and Fig. 8.

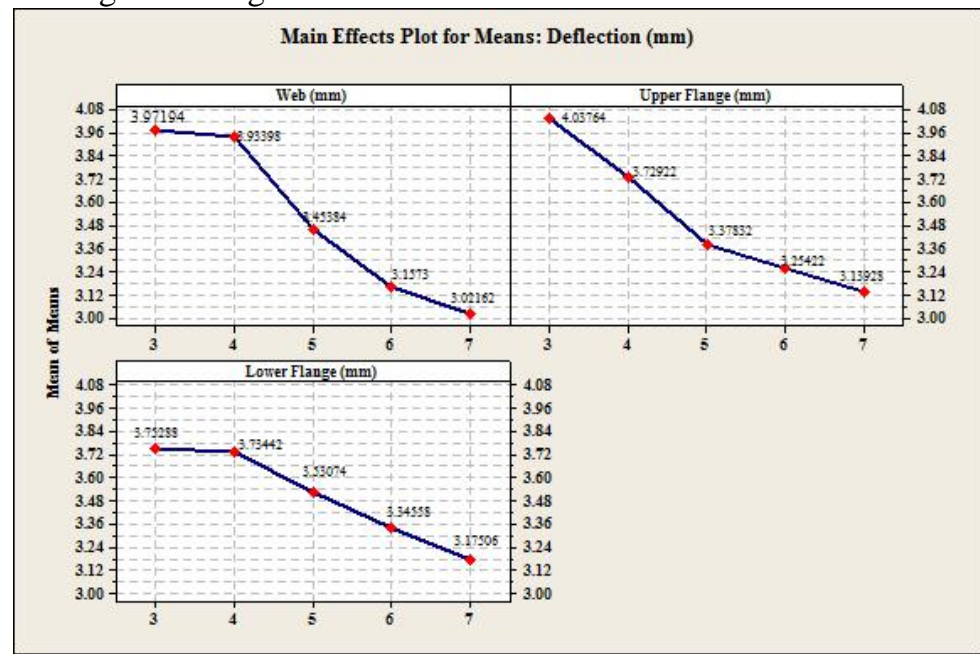

Fig. 7: Main Effects Plot for Mean data: deflection

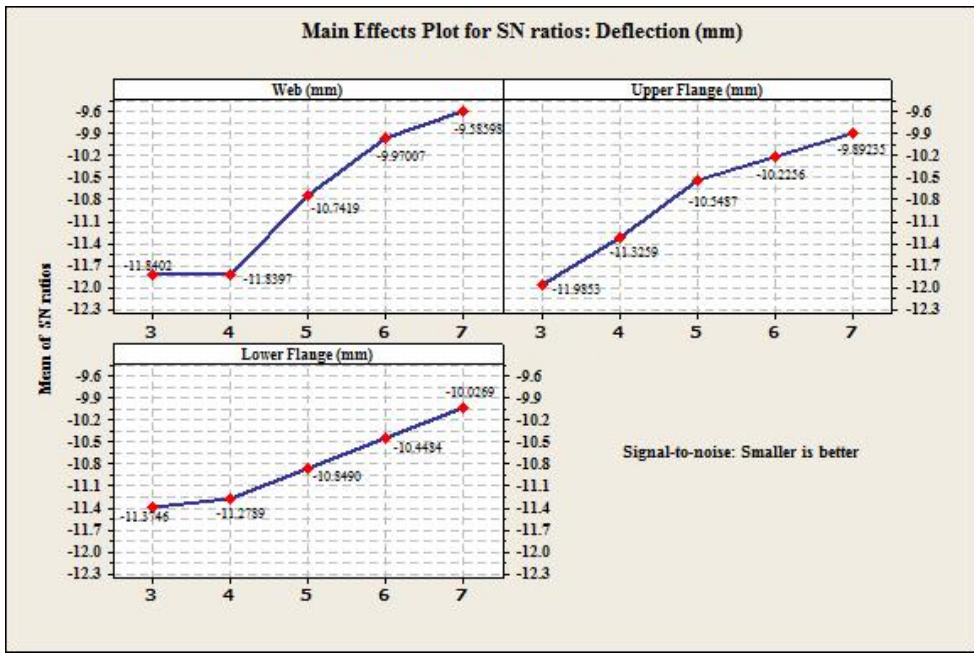

Fig. 8: Main Effects Plot for S/N ratio data: Deflection

According to deflection span ratio allowable deflection for overhanging beam is $1 / 300$. So for $6355 \mathrm{~mm}$ length allowable deflection for simply supported beam is $21.18 \mathrm{~mm}$. Fig. 7 and Fig. 8 shows following effects:

- $\quad$ As the web thickness of chassis frame is varied from $3 \mathrm{~mm}$ to $7 \mathrm{~mm}$, the deflection developed in chassis decreased from $3.97194 \mathrm{~mm}$ to $3.02162 \mathrm{~mm}$.

- $\quad$ As the Upper flange thickness of chassis frame is varied from $3 \mathrm{~mm}$ to $7 \mathrm{~mm}$, the deflection developed in chassis decreased from $4.03764 \mathrm{~mm}$ to $3.13928 \mathrm{~mm}$.

- $\quad$ As the lower flange thickness of chassis frame is varied from $3 \mathrm{~mm}$ to $7 \mathrm{~mm}$, the deflection developed in chassis decreased from $3.75288 \mathrm{~mm}$ to $3.17506 \mathrm{~mm}$.

The deflections for all the value of web, upper flange and lower flange thickness are within the safe limit. in Table 5.

From the above analysis the Optimum set of parameters which is having the minimum weight is given 
Table 5: Optimum set of parameter and Predicted Value of stress

\begin{tabular}{|c|c|c|c|}
\hline $\begin{array}{c}\text { Web Thickness } \\
(\mathbf{m m})\end{array}$ & $\begin{array}{c}\text { Upper Flange } \\
\text { Thickness } \\
(\mathbf{m m})\end{array}$ & $\begin{array}{c}\text { Lower Flange } \\
\text { Thickness } \\
(\mathbf{m m})\end{array}$ & $\begin{array}{c}\text { Predicted Value of stress } \\
\text { MPa }\end{array}$ \\
\hline 5 & 4 & 4 & 119.461 \\
\hline
\end{tabular}

\section{Validation Of Taguchi Result}

The model of modified chassis as per the dimension given in Table 5 is created in solid works 2009 as shown on Fig. 9.The model is then saved in IGES format which can be directly imported into ANSYS workbench.

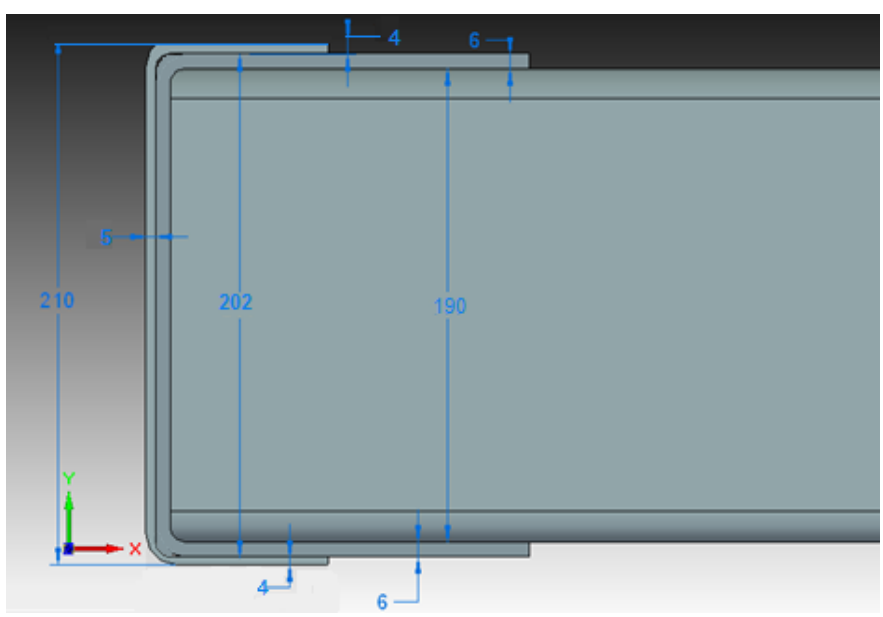

Fig. 9: Modeling of modified section

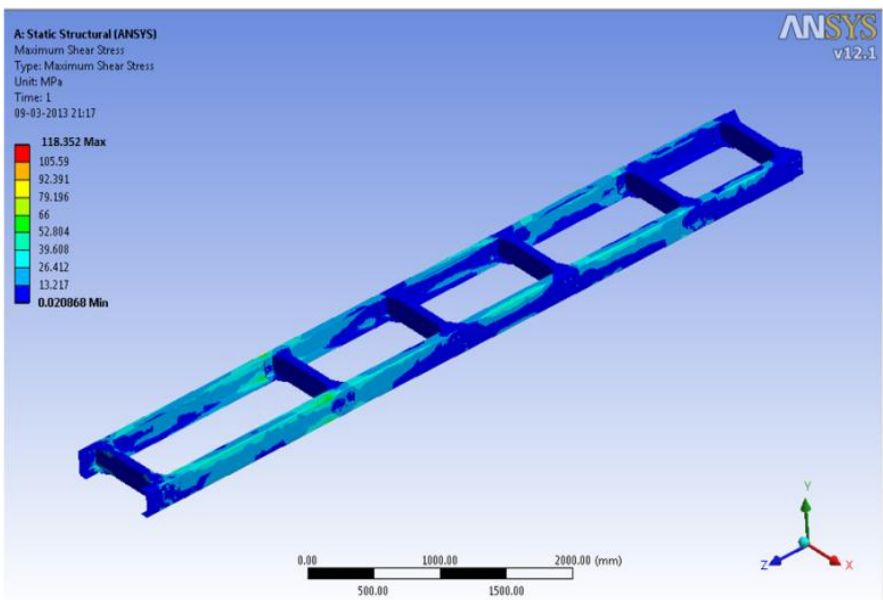

Fig. 10: Shear stress in modified chassis

The generated shear stresses $(118.352 \mathrm{MPa})$ are less than the permissible value (120 MPa) so the design is safe. The shear stress is as shown in Fig. 10.

Table 6: Variation in results of Taguchi and FEA

\begin{tabular}{|c|c|c|}
\hline $\begin{array}{c}\text { Predicted Value of stress } \\
\text { MPa }\end{array}$ & $\begin{array}{c}\text { FEA Result of stress } \\
\text { MPa }\end{array}$ & \% Variation \\
\hline 119.461 & 118.352 & 0.9283 \\
\hline
\end{tabular}


Table 7: Reduction in Weight of chassis

\begin{tabular}{|c|c|c|}
\hline $\begin{array}{c}\text { Weight of Actual Chassis } \\
\mathbf{~ K g}\end{array}$ & $\begin{array}{c}\text { Weight of Modified Chassis } \\
\mathbf{~ K g}\end{array}$ & $\begin{array}{c}\text { Weight Reduction } \\
\mathbf{\%}\end{array}$ \\
\hline 321.25 & 279.44 & 13.01 \\
\hline
\end{tabular}

The generated shear stresses are less than the permissible value so the design is safe. The analysis gives maximum shear stress which is within desired limit and it is also nearer to Taguchi's prediction as shown in Table 6.

This percentage variation is caused by uncertainties of Taguchi Prediction and accuracy of FEA.

\section{Conclusion}

The FEM-based Taguchi methods have effectively decreased the time and efforts required for evaluating the design variables of implants.

The optimal parameter combination for the minimum weight with permissible value of stress is obtained by using the analysis of $\mathrm{S} / \mathrm{N}$ ratio. According to the results $5 \mathrm{~mm}$ Web thickness, $4 \mathrm{~mm}$ Upper Flange thickness and $4 \mathrm{~mm}$ Lower Flange thickness are the optimal parameters for permissible stress.

FEA results obtained from the confirmation analysis using optimum combination are shown excellent agreement with the predicated result. Weight reduction achieved by FEA-DOE hybrid modeling is $13.01 \%$ as shown in Table 7.

\section{Journal Papers:}

\section{REFERENCES}

[1] Wen-Hsien Hsua, Ching-Kong Chaoa, Hsi-Ching Hsub, Jinn Lin b, Ching-Chi Hsua, Parametric study on the interface pullout strength of the vertebral body replacement cage using FEM-based Taguchi methods, Medical Engineering \& Physics 31, 2009, 287294.

[2] Bappa Acherjee, Arunanshu S. Kuar, Souren Mitra, Dipten Misra, Modeling of laser transmission contour welding process using FEA and DoE, Optics \& Laser Technology 44-5, 2012 1281-1289

\section{Books:}

[3] J.P. Vidosic, Machine Design Project (New York, US: Ronald Press, 1957).

[4] Antonio Pratelli, C. A. Brebbia, Urban Transport Seventeen, Part XVII (Southampton, UK: WIT Press, 1966).

[5] PSG Design Data Book for Standard Data (Kalaikathir Achchagam, Coimbatore2004).

\section{Thesis:}

[6] Ajaykumar Menon, Structural optimization using Ansys and regulated multi-quadric response surface model, The University Of Texas, Arlington, 2005

[7] Brian J. Auer, Size and shape optimization of frame and truss structures through evolutionary methods, University of Idaho, 2005

\section{Proceedings Papers:}

[8] D. M. Chauhan, Prof. S. B. Soni and Prof. A. M. Gohil, Parametric Optimization of Hydraulic Modular Trailer Frame using ANSYS (APDL), Proc. 2006 Nirma University International Conference on Engineering, Nirma University, Ahmedabad,2006. 